\title{
Effect of reduced exposure times on the cytotoxicity of resin luting cements cured by high-power led
}

\author{
Gulfem ERGUN¹, Ferhan EGILMEZ², Sukran YILMAZ³
}

1- DDS, PhD, Associate Professor, Department of Prosthodontics, Faculty of Dentistry, Gazi University, Ankara, Turkey.
2- DDS, PhD, Research Associate, Department of Prosthodontics, Faculty of Dentistry, Gazi University, Ankara, Turkey.
3- MSc, Chief, Foot and Mouth Disease Institute, Ankara, Turkey.

Corresponding address: Dr. Gulfem ERGUN - Suslu sok. No.14/9 - Mebusevleri, Tandogan - 06580 - Ankara-Turkey - Phone: + 903122034191 (work) / + 903122139701 (home) - Fax: +90-312-223-92-26 - e-mail: gulfem@gazi.edu.tr - ergungulfem@yahoo.com

Received: July 23, 2009 - Modification: March 26, 2010 - Accepted: April 29, 2010

\section{ABSTRACT}

O bjective: Applications of resin luting agents and high-power light-emitting diodes (LED) light-curing units (LCUs) have increased considerably over the last few years. However, it is not clear whether the effect of reduced exposure time on cytotoxicity of such products have adequate biocompatibility to meet clinical success. This study aimed at assessing the effect of reduced curing time of five resin luting cements (RLCs) polymerized by high-power LED curing unit on the viability of a cell of L-929 fibroblast cells. Material and Methods: Disc-shaped samples were prepared in polytetrafluoroethylene moulds with cylindrical cavities. The samples were irradiated from the top through the ceramic discs and acetate strips using LED LCU for $20 \mathrm{~s}$ ( $50 \%$ of the manufacturer's recommended exposure time) and $40 \mathrm{~s}$ ( $100 \%$ exposure time). After curing, the samples were transferred into a culture medium for $24 \mathrm{~h}$. The eluates were obtained and pipetted onto L-929 fibroblast cultures ( $3 \times 10^{4}$ per well) and incubated for evaluating after $24 \mathrm{~h}$. Measurements were performed by dimethylthiazol diphenyltetrazolium assay. Statistical significance was determined by two-way ANOVA and two independent samples were compared by t-test. Results: Results showed that eluates of most of the materials polymerized for $20 \mathrm{~s}$ (except Rely X Unicem and Illusion) reduced to a higher extent cell viability compared to samples of the same materials polymerized for $40 \mathrm{~s}$. Illusion exhibited the least cytotoxicity for $20 \mathrm{~s}$ exposure time compared to the control (culture without samples) followed by Rely X Unicem and Rely X ARC (90.81\%, 88.90\%, and $83.11 \%$, respectively). For Rely X ARC, Duolink and Lute-It $40 \mathrm{~s}$ exposure time was better $(t=-1.262 p=0,276 ; t=-9.399 p=0.001 ;$ and $t=-20.418$ $\mathrm{p}<0.001$, respectively). Conclusion: The results of this study suggest that reduction of curing time significantly enhances the cytotoxicity of the studied resin cement materials, therefore compromising their clinical performance.

Key words: Cytotoxicity. Resin cements. Dental curing lights. Exposure time.

\section{INTRODUCTION}

Resin cements are widely used in the luting of composite resin or porcelain inlays, porcelain laminate veneers, resin bonded metallic prosthesis and ceramic restoratives using Computer aided design and manufacturing (CAD/CAM $)^{19}$.

Different types of light-curing units (LCUs) have been proposed for the photopolymerization of light activated restorative materials including conventional quartz tungsten halogen (QTH) lights and new photoactivation techniques, such as intermittent light ${ }^{23}$, plasma arc curing (PAC) ${ }^{25}$ and, more recently, a new technology employing light-emitting diode (LED) ${ }^{14}$ or laser ${ }^{27}$.

Solid-state LEDs use junctions of doped semiconductors ( $p-n$ junctions) based on gallium nitride to emit blue light. The spectral output of blue LEDs falls between 450 and $490 \mathrm{~nm}$, so these units are effective for curing materials with camphorquinone photo-initators. LED units do not require a filter, have a long life span, and do not produce as much heat as quartz-tungsten halogen devices ${ }^{21}$. To date there is no internationally 
accepted classification of the various types of LED curing lights. Most of the first-generation LED LCUs were unable to cure composites as well as correctly functioning QTH lights ${ }^{15,27}$. However, LED technology has advanced and it has been reported that high power "second-generation LED curing lights" can polymerize some resins as well as or better than some QTH lights ${ }^{15}$. Many of the newer LED lights deliver more than $400 \mathrm{~mW} / \mathrm{cm}^{2}$. High power LEDs have since made it possible to merge the technical developments in dental curing lights, allowing LED-based systems to achieve a $50 \%$ reduction in cure time from that recommended by manufacturers. This would be favorable for dentists as well as for patients. However, this shorter exposure time may lead to an insufficient degree of conversion of the resin cement. Especially at the bottom of restoration, this may lead to reduced physical properties and poor biocompatibility when ceramic restoration thickness ( $>2 \mathrm{~mm}$ ) is difficult to cure well from standard light source position for several ceramic crowns.

The degree of light induced conversion of monomers to polymers is influenced by various parameters, such as the intensity of the light around the wavelength triggering level, the photoinitator system, the duration of irradiation, concentrations, types and mixtures of photoinitators, co-initators, stabilizers and inhibitors, as well as the types and proportions of monomers and fillers ${ }^{22}$. Adequate polymerization is the most important factor in maximizing the physical properties, clinical performance and biocompatibility. Problems associated with inadequate polymerization include inferior physical properties, solubility in the oral environment and increased microleakage with resultant recurrent decay and pulpal irritation. On the other hand, the amount of leachable residual monomers may vary with the light source used for curing ${ }^{15}$. Although amongst the different LCUs available in dental practice, halogen lamps are the most frequently used, recently the LED technology has been successfully proposed ${ }^{15}$.

The adhesive properties depend on direct contact between the cement and the mineralized tissues. Luting agents contact a large area of dentin when used for crown cementation. However, luting agents generally appear to cause little adverse long term pulpal effect, particularly if the remaining dentin thickness exceeds $1 \mathrm{~mm}^{24}$. Therefore, the biocompatibility of resin luting cements (RLCs) is important for the optimal advantage of these materials in clinical use 28 .

There is little information on biocompatibility tests, especially on the effect of reduced exposure time on cytotoxicity for luting resin cements which is directly related to clinical success of the prosthetic restorations.
This study aimed at assessing the effect of reduced curing time of five RLCs polymerized by high-power LED curing unit on the viability of a cell of L-929 fibroblast cells over $24 \mathrm{~h}$.

\section{MATERIAL AND METHODS}

\section{Cells}

The cells used for the experiments were L-929 mouse fibroblasts (L-929 An2 HÜKÜK 95030802; Food and Mouth Disease Institute, Ankara, Turkey) in conformity with the ISO $10993-5^{13}$ standard. The cells were grown as monolayer cultures in T-25 flasks (Costar, Cambridge, MA, USA), subcultured three times a week at $37^{\circ} \mathrm{C}$ in an atmosphere of $5 \% \mathrm{CO}_{2}$ in air and $100 \%$ relative humidity and maintained at third passage. The culture medium was Dulbecco's modified Eagle medium (DMEM)/Ham's F12 nutrient mixture (1:1; Sigma, St Louis, MO, USA) supplemented with $10 \%(\mathrm{v} / \mathrm{v}$ ) foetal bovine serum (FBS; Biochrom, Berlin, Germany) without antibiotics. Adherent cells at a logarithmic growth phase were controlled under an inverted tissue culture microscope (Olympus CK40, Tokyo, Japan) and detached with a mixture of $0.025 \%$ trypsin (Sigma) and $0.02 \%$ ethylenediaminetetraacetic acid (EDTA; Sigma), incubated for $2-5 \mathrm{~min}$ at $37^{\circ} \mathrm{C}$ and used for cell inoculation.

\section{Sample preparation}

Five dual polymerizing luting resin cements were used in this study: RelyX Unicem (RU, 3M ESPE Dental Products, St. Paul, USA); Duolink (DK, Bisco, Inc. Schaumburg, IL, USA); Lute-It (LT, Pentron Clinical Technologies, L.L.C., Wallingford, USA); Illusion (IN, Bisco, Inc. Schaumburg, IL, USA); Rely X ARC (RA, 3M ESPE Dental Products, St. Paul, USA) The tested materials and their compositions are listed in Figure 1. Photoactivation was performed with the LED LCU (Elipar Freelight 2, 3M ESPE, 939820014022, Seefeld, Germany). Forty disc-shaped samples ( $6 \mathrm{~mm}$ diameter $\mathrm{x} 1$ $\mathrm{mm}$ thickness) were prepared for each tested material: 20 disc samples exposed with LED LCU for $20 \mathrm{~s}$ and remaining 20 disc samples exposed for 40 s. Standard exposure mode, providing full light intensity for the entire exposure, was chosen with both $40 \mathrm{~s}$ and $20 \mathrm{~s}$. The LED LCU had a light guide tip diameter of $8 \mathrm{~mm}$ with irradiance of $1200 \mathrm{~mW} /$ $\mathrm{cm}^{2}$ with a wavelength of $430-480 \mathrm{~nm}$ according to the manufacturer.

The RLCs were placed into sterile circular polytetrafluoroethylene moulds. Polyethylene films were added on the top surface of the luting resin cements. Therefore to simulate clinical conditions, the tested materials were irradiated from the top through the ceramic discs ( $1 \mathrm{~cm}$ diameter $\times 2$ 


\begin{tabular}{|c|c|c|c|c|c|}
\hline Trade Name & Composition & $\begin{array}{c}\text { Manufacturer's } \\
\text { Polymerizing Time }\end{array}$ & Compounds & $\begin{array}{c}\text { LOT } \\
\text { Number }\end{array}$ & Manufacturer \\
\hline $\begin{array}{l}\text { RelyX Unicem } \\
\text { (RU) }\end{array}$ & $\begin{array}{c}\text { Powder: } \\
\text { Glass Powder,Initiator, } \\
\text { Silica Substituded Pyrimidine, } \\
\text { Calciumhydroxide, } \\
\text { Peroxy compound, } \\
\text { Pigment } \\
\text { Liquid: } \\
\text { Methacrylated phosphoric ester, } \\
\text { Dimethacrylate, Acetate, } \\
\text { Stabiliser,Initiator }\end{array}$ & $40 \mathrm{~s}$ & $\begin{array}{l}\text { Powder } \\
\text { Liquid }\end{array}$ & 213198 & $\begin{array}{c}\text { 3M ESPE Dental } \\
\text { Products, }\end{array}$ \\
\hline $\begin{array}{l}\text { Duolink } \\
\text { (DK) }\end{array}$ & $\begin{array}{c}\text { Base: } \\
\text { Bis - GMA, TEGDMA, } \\
\text { Glass filler, UDMA } \\
\text { Catalyst: } \\
\text { Bis - GMA, TEGDMA, } \\
\text { Glass filler }\end{array}$ & $40 \mathrm{~s}$ & & 400003526 & Bisco, Inc. \\
\hline $\begin{array}{l}\text { Lute-It } \\
\text { (LT) }\end{array}$ & $\begin{array}{c}\text { Base: } \\
\text { Bis - GMA, UDMA, HDDMA, } \\
\text { Barium borosilicate glass fillers, } \\
\text { Inorganic fluoride, } \\
\text { Silica,Silane photoinitator, } \\
\text { Amine and inorganic pigments } \\
\text { Catalyst: } \\
\text { Benzoyl peroxide and stabilizers }\end{array}$ & $40 \mathrm{~s}$ & & $\begin{array}{c}\text { Base: } \\
100826 \\
\text { Catalyst: } \\
96393\end{array}$ & $\begin{array}{l}\text { Pentron Clinical } \\
\text { Technologies, }\end{array}$ \\
\hline $\begin{array}{l}\text { Illusion } \\
\text { (IN) }\end{array}$ & $\begin{array}{c}\text { Base: } \\
\text { EBPADMA, dental glass, } \\
\text { TEGDMA } \\
\text { Catalyst: } \\
\text { Bis - GMA, dental glass, } \\
\text { TEGDMA } \\
\end{array}$ & $40 \mathrm{~s}$ & & $\begin{array}{c}\text { Base: } \\
400003895 \\
\text { Catalyst: } \\
400003894\end{array}$ & Bisco, Inc. \\
\hline $\begin{array}{c}\text { Rely X ARC } \\
\text { (RA) }\end{array}$ & $\begin{array}{c}\text { Paste A: } \\
\text { Bis - GMA, TEGDMA, } \\
\text { Zirconia/Silica filler, } \\
\text { Pigments, amine and } \\
\text { photoinitator system } \\
\text { Paste B: } \\
\text { Zirconia/Silica filler, } \\
\text { Benzoyl peroxide. }\end{array}$ & $40 \mathrm{~s}$ & $\begin{array}{l}\text { Paste A } \\
\text { Paste B }\end{array}$ & $3415 \mathrm{~A} 3$ & $\begin{array}{c}\text { 3M ESPE Dental } \\
\text { Products, }\end{array}$ \\
\hline
\end{tabular}

Bis - GMA: Bisphenol A diglycidyl methacrylate; UDMA: Urethane dimethacrylate; HDDMA: 1,6-hexanediol dimethacrylate; TEGDMA: Triethyleneglycol dimethacrylate; EBPADMA: Ethoxylated bisphenol A dimethacrylate

Figure 1- Tested materials and their composition according to manufacturers.

mm thickness, IPS Empress 2; Shade 1A, Lot: D 50108, Ivoclar, Vivadent, FL-9494, Schaan, Liechtenstein) by contacting the end of the light guide with its surface, through the use of LED LCU for $20 \mathrm{~s}$ ( $50 \%$ of the recommended exposure time) and $40 \mathrm{~s}$ (100\% exposure time) (Figure 2), under aseptic conditions at laminar flow (Holten, Class II, Denmark). The freshly prepared samples were placed immediately at the bottom of 6-well plates (Costar, Cambridge MA, USA).

The ratio of the surface area of the disc samples to the extraction volume was $0.5 \mathrm{~cm}^{2} \mathrm{~mL}^{-1}$ which is in line with ISO $10993-12^{14}$, in this study. The samples were placed in DMEM/F12 with $10 \%$ FBS and incubated at $37^{\circ} \mathrm{C}$ in an atmosphere of $5 \% \mathrm{CO}_{2}$ in air without agitation for $24 \mathrm{~h}$ incubation period. After the incubation, the extracts were filtered through $0.22 \mu \mathrm{m}$ cellulose acetate filters (Millipore; Sigma, St. Louis, MO, USA) and then they were used to evaluate cytotoxicity. 


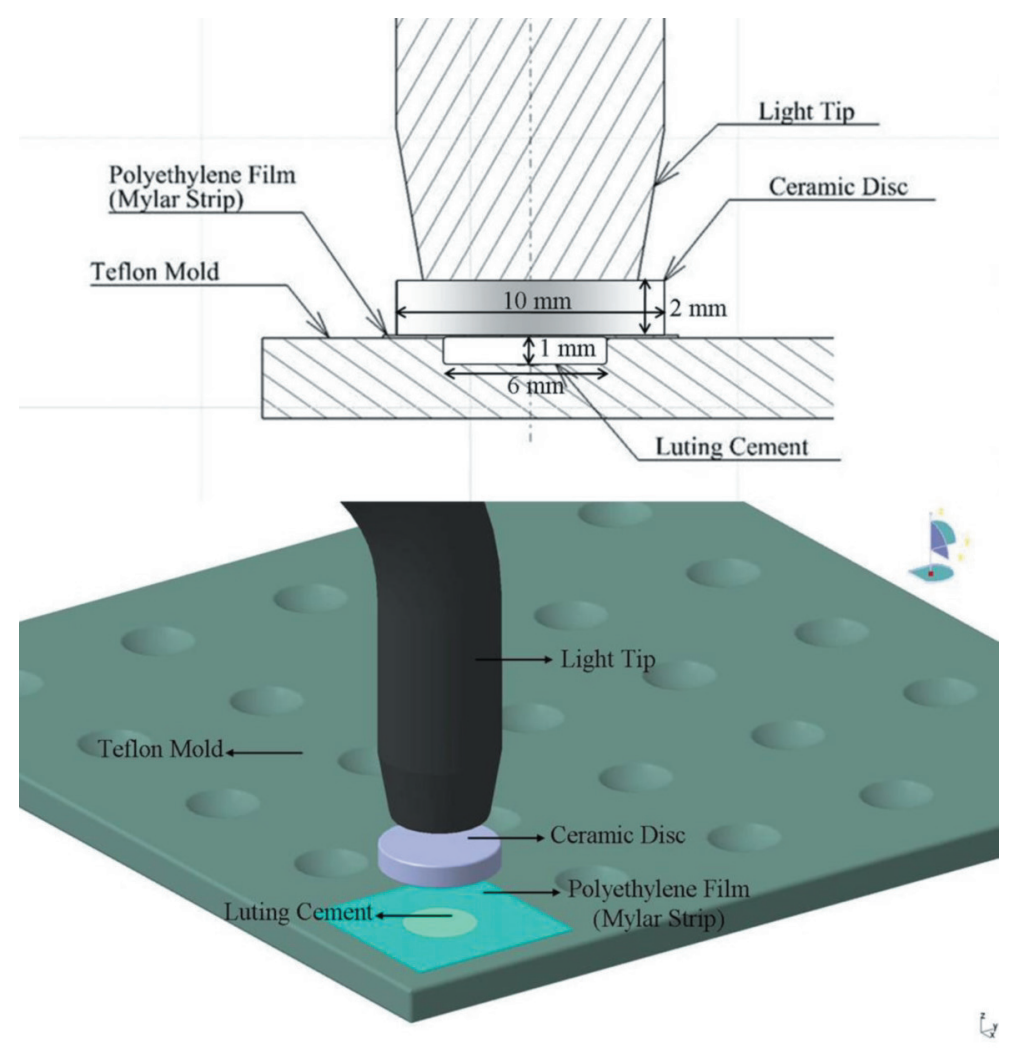

Figure 2- Schematic illustration of sample preparation

\section{Cytotoxicity testing (MTT assay)}

The L-929 cell suspension with DMEM/F12 with $10 \%$ FBS and $1 \%$ antibiotic was prepared at a concentration of $3 \times 10^{4}$ cell $\mathrm{mL}^{-1}$ and inoculated onto 96-well cluster cell culture plates $(100 \mu \mathrm{L}$ per well). The multiwell plates were incubated at $37^{\circ} \mathrm{C}, 5 \% \mathrm{CO}_{2}$ in air for $24 \mathrm{~h}$. After $24 \mathrm{~h}$, the culture medium was removed from the wells and equal volumes $(100 \mu \mathrm{L})$ of the extracts were added into each well. In control wells, $100 \mu \mathrm{L}$ DMEM/F12 with $10 \%$ FBS and $1 \%$ antibiotic was added. Then 96-well cluster cell culture plates were incubated for $24 \mathrm{~h}$ at $37^{\circ} \mathrm{C}$. After the $24 \mathrm{~h}$ incubation period test extracts were removed. Following removal of the test extracts, $100 \mu \mathrm{L}^{\text {well }}{ }^{-1}$ DMEM/F12 with $10 \%$ FBS and $1 \%$ antibiotic and $12 \mu \mathrm{L}$ MTT (tetrazolium salt 3-[4,5-dimethylthiazol-2-yl]-2,5diphenyltetrazolium bromide) were added to each well and incubated in a dark environment for $4 \mathrm{~h}$ at $37^{\circ} \mathrm{C}$. After incubation 96 wells were checked for formazan crystals with inverted tissue culture microscope. MTT was aspirated and $100 \mu \mathrm{L}^{\text {well }}{ }^{-1}$ of isopropanol (Merck, Darmstadt, Germany) was added to each well. Subsequently, the absorbance at $570 \mathrm{~nm}$ was measured using a UV-visible spectrophotometer (LPB Pharmacia, Bromma, Sweden).

Then the absorbance results were evaluated under a light microscope and calculated as a percentage of the controls. Triplicate experiments were performed throughout this study.

\section{Statistical analysis}

The cytotoxic effects of the RLCs polymerizing with LED LCU and the exposure times on the fibroblast cell's survival rates were evaluated by two way analysis of variances. Then, two independent samples were compared by t-test. All statistical analysis was performed by using SPSS 11.5 statistical software package (SPSS Inc, Chicago, IL, USA).

\section{RESULTS}

The results in Figure 3 demonstrated that all freshly prepared RLCs polymerized with LED for 20 s ( $50 \%$ exposure time) and $40 \mathrm{~s}(100 \%$ exposure time) reduced the cell numbers compared to the control (culture without sample).

The cytotoxic effect of the tested materials and exposure times on the cell survival rates were evaluated by two-way analysis of variance. There was a significant two-way interaction between two factors $(F=5.856, p=0.003)$. Therefore, the time factor levels were compared in each RLC (two independent samples were compared by $t$-test). It was observed that the cytotoxicity of the tested materials depends on the exposure time.

When the interactions between exposure times and RLCs are evaluated, both DK and LT reduced cell survival rate significantly with respect to the control for $20 \mathrm{~s}$ and $40 \mathrm{~s}(\mathrm{p}<0.001)$ (Table 1$)$.

Cell survival rate results for $40 \mathrm{~s}$ exposure time 
were significantly higher than $20 \mathrm{~s}$ cell survival rates of $\mathrm{DK}$ and $\mathrm{LT}(\mathrm{t}=-9.399, \mathrm{p}=0.001$; and $\mathrm{t}=$ 20.418, $\mathrm{p}<0.001$, respectively).

There is no significant difference between the exposure time results for RU, RA and IN. However, in terms of cell survival rate, the $20 \mathrm{~s}(50 \%$ exposure time) results for RU and IN were higher than the $40 \mathrm{~s}(100 \%$ exposure time) results for RA $(t=1.747, p=0.156 ; t=0.164, p=0.878 ;$ and $t=-1.262, p=0.276$, respectively).

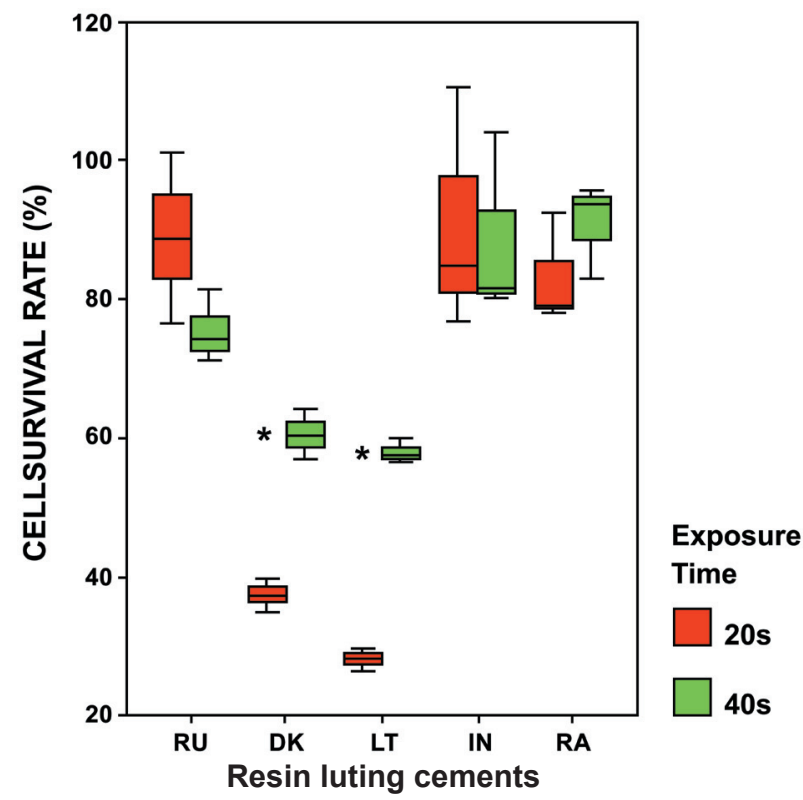

Figure 3- Distribution of cell survival rates (\%) according to the light exposure times $(100 \%$ and $50 \%)$ for each resin luting cements. Cell survival rates are expressed as a percentage of controls (cultures without samples). Bars show the mean and standard deviations of three independent experiments. $\mathrm{RU}=$ Rely $\mathrm{X}$ Unicem; $\mathrm{DK}=$ Duolink; LT= Lute - It; IN= Illusion; RA= Rely X ARC

\section{DISCUSSION}

In the present study, L929 fibroblasts were used because they are the most common ISO $^{13}$-approved cell type in the pulp and gingival tissues, which would be the target of chemicals released from the RLCs. It has been demonstrated that $L 929$ mouse fibroblasts show comparable results to primary human gingival fibroblasts and therefore might represent a model for gingival toxicity in vitro ${ }^{8}$. Several in vitro studies assessing the cytotoxicity of dental materials have used fibroblast cell lines because they represent a common cell type in pulp and gingival tissues and also because of their reproducible growth rates, and advantages in handling and availability compared to primary cells ${ }^{9,16}$.

In this study, the freshly prepared samples were placed in medium immediately. It is important for the materials to be tested immediately after mixing/ curing to avoid the loss of toxic substances released from the tested material at this initial stage.

A recent study demonstrated the relevance of the cytotoxicity of RLCs and the importance of achieving sufficient polymerization with the LCUs ${ }^{12}$. Elipar Freelight 2, used in the present study, is a high-intensity LED LCU, and has exposure time options as follows: 5, 10, 15 and 20 s according to the manufacturer's instructions. Because of the high light intensity $\left(1200 \mathrm{~mW} / \mathrm{cm}^{2}\right)$ of this $\mathrm{LCU}$, these time periods correspond to the time periods $(10,20,30$ and $40 \mathrm{~s})$ of conventional LCU that has light intensity of $600-800 \mathrm{~mW} / \mathrm{cm}^{2}$ for halogen technology or $300-400 \mathrm{~mW} / \mathrm{cm}^{2}$ light intensity for LED. Thus, the normal exposure time for conventional units can be cut in half without compromising curing performance but it could have a direct affect on biocompatibility of the RLCs.

Feng, et al. ${ }^{7}$ (2009) evaluated the curing sufficiency under the condition of high irradiance and short irradiation time on methacrylate-based dental materials by using plasma arc and quartz

Table 1- Cell survival rate (CSR) according to the light exposure times for each resin luting cement

\begin{tabular}{|c|c|c|c|c|c|c|}
\hline \multirow{3}{*}{$\begin{array}{l}\text { RESIN LUTING } \\
\text { CEMENTS }\end{array}$} & \multicolumn{4}{|c|}{ LIGHT EXPOSURE TIMES } & \multicolumn{2}{|c|}{ T-Test } \\
\hline & \multicolumn{2}{|c|}{20 s (50\%) } & \multicolumn{2}{|c|}{40 s $(100 \%)$} & \multirow[t]{2}{*}{ t value } & \multirow[t]{2}{*}{$p$ value } \\
\hline & $\begin{array}{l}\text { CSR \% } \\
\text { (Mean) }\end{array}$ & $\begin{array}{l}\text { Standard } \\
\text { Deviation }\end{array}$ & $\begin{array}{l}\text { CSR \% } \\
\text { (Mean) }\end{array}$ & $\begin{array}{l}\text { Standard } \\
\text { Deviation }\end{array}$ & & \\
\hline Rely X Unicem (RU) & 88.90 & 12.25 & 75.53 & 5.07 & 1.747 & 0.156 \\
\hline Duolink (DK) & 37.30 & 2.34 & 60.44 & 3.56 & -9.399 & $0.001^{*}$ \\
\hline Lute - It (LT) & 28.10 & 1.68 & 57.86 & 1.87 & -20.418 & $<0.001^{*}$ \\
\hline Illusion (IN) & 90.81 & 17.67 & 88.71 & 13.41 & 0.164 & 0.878 \\
\hline Rely X ARC (RA) & 83.11 & 8.03 & 90.91 & 6.85 & -1.262 & 0.276 \\
\hline
\end{tabular}

* as compared to the control (cultures without sample) for $20 \mathrm{~s}$ and $40 \mathrm{~s}$ 
tungsten halogen curing lights. Higher irradiance and shorter irradiation time was found intrinsically associated with a higher free radical termination rate than that of lower irradiance but longer irradiation time. On the other hand, there is no information about the cytotoxicity of the RLCs in half the exposure time with polymerized high power LED. RLCs contain initially unbound components ${ }^{9}$. Light polymerizing of RLCs will polymerize resins in solid phase hence significantly diminishing the amount of free monomer and substantially reducing the potential for noxious stimuli. Complete polymerization would suppress all stimuli. Forever polymerized resin never fully polymerized, they will degrade by time ${ }^{6}$.

Uhl, et al. ${ }^{29}$ (2002) have addressed the application of LED technology to cure restorative materials. Typically, the advantages claimed for second-generation LED LCUs are more efficiency in cure, decreased heat from the light tip, consistent output over time without degradation and significantly longer useful life of the diodes compared with quartz tungsten halogen bulbs ${ }^{20}$. Furthermore, with the introduction of LED LCUs, it was asserted that the emission of blue LED LCUs is the ideal spectra for the conversion of dental materials containing monomer. In this way, fewer toxic substances may leach into the environment ${ }^{3}$. Biocompatibility of light-cured dental materials may be affected by the quality of the LCU used. Due to the advanced LED technology, high power LED curing light was able to polymerize dental resin in half exposure time (50\%) instead of $100 \%$.

RLCs cover the dentin walls and only indirectly interact with the pulp, by means of the tubular fluid, or with the oral mucosa, by means of saliva ${ }^{1}$. An in vitro study has shown that cellular toxicity of RLCs was related to leachables containing free monomers and components such as degradation products or non reactive initiators, activators, and/or stabilizers ${ }^{5}$. Piva, et al. ${ }^{26}$ (2008) reported that degree of polymerization of RLC is influenced by several factors, namely, porcelain shade and thickness, LCU and curing time. Inadequate degree of polymerizing is therefore necessary to improve the biocompatibility of RLCs used in prosthetic dentistry. The tested samples were irradiated from top through the ceramic disc in the present study, so as to simulate clinical condition. Insufficient photoactivation contributes to an increase in level of unreacted monomers through a reduced degree of polymerization and cross linking. When light curing of RLCs are not fully polymerized, leachable components such as Bis-GMA, UDMA, TEGDMA, camphorquinone and HEMA, may penetrate through dentin tubules, exert potential pulpal injury and inhibit pulp tissue repair $^{1,28}$. According to Goldberg ${ }^{10}$ (2008), these monomers are cytotoxic in vitro for pulp and gingival cells. Leaching of some ions may cause cell alterations, and some molecular mechanisms have been identified as key factors leading to apoptosis and/or pulp necrosis. Bakopoulou, et al. ${ }^{2}$ (2009) investigated the genotoxic and cytotoxic effects of eluates derived from different types of dental cements on normal cultured human lymphocytes and reported that the released substances, such as TEGDMA included in resin cements' composition are responsible for the cytogenetic effects. A previous study demonstrated that the cytotoxicity ranking of the most widely used monomers was BisGMA > UDMA > TEGDMA $>$ HEMA $>M_{M A}{ }^{30}$. Furthermore, a correlation between fluoride release and cytotoxicity has been observed by Khalil and Da'dara $^{18}$ (1994), reporting that high doses of fluoride inhibited cell division and caused death of rat bone marrow cells. In the current study, DK and LT showed higher cytotoxicity with both exposure times in comparison to the other tested materials. This is considered that UDMA and inorganic fluoride in structure of these materials may be responsible for their cytotoxic effect, as it has been previously shown that UDMA ${ }^{4,11}$ and fluoride ${ }^{17}$ are more toxic agents. Furthermore, it is considered that synergistic effects of Bis-GMA and UDMA released by those tested materials lead to increased cytotoxicity on L-929 fibroblast cells.

It was clear that all sufficient quantities of test materials polymerized by high power LED for 20 $\mathrm{s}$ and $40 \mathrm{~s}$ leached a variety of components into cell culture medium and affected cell activity. After testing the cytotoxicity of polymerized test samples, statisticially significant differences were found regarding cell survival rates for the different exposure times and RLCs. When comparing the control cultures LT polymerized for $20 \mathrm{~s}$ (50\%) had resulted in the lowest survival rate of $28 \%$. However, IN polymerized for 20 s revealed the highest cell survival rate of $90.81 \%(p<0.01)$. In the $40 \mathrm{~s}$ exposure time, LT had led to the lowest survival rate $(57.86 \%)$ while RA had brought about the highest survival rate $(90.91 \%)$ compared to the control cultures $(p<0.01)$.

The results revealed that there might be several possible reasons for different effects of RLCs or exposure times ( $50 \%$ and $100 \%$ ) on their cytotoxicity such as the light transmission characteristic, the released energy during the polymerization of the RLCs and the amount as well as type of released toxic substances from the unpolymerized RLCs. Generally, when the results of all samples were evaluated, materials polymerized for 20 s (except for RU, IN) had reduced cell survival rates than the samples polymerized for $40 \mathrm{~s}$ with high power LED. This leads to the assumption that 20-s exposure time is not sufficient for the 
polymerization of these materials.

The obtained results indicate that the RLCs polymerized for either 20 s or 40 s with high power LED may lead to unpolymerized components or toxic substances with harmful effects since they might penetrate through dentin tubules. The findings of the present study also suggest that it is important to be cautious when considering manufacturers' recommendation that high power LED light cure unit reduces the exposure time of RLCs in polymerization by $50 \%$.

\section{CONCLUSIONS}

Based on the experimental condition, it was concluded that the period of photoactivation is related to the cytotoxic effects of the tested RLCs, and that an exposure time of $40 \mathrm{~s}$ is recommended for DK, LT and RA although $20 \mathrm{~s}$ is preferable for $\mathrm{RU}$ and IN in operative procedures.

\section{REFERENCES}

1- Annunziata M, Aversa R, Apicella A, Annunziata A, Apicella D, Buonaiuto $C$, et al. In vitro biological response to a light-cured composite when used for cementation of composite inlays. Dent Mater. 2006;22(12):1081-5.

2- Bakopoulou A, Mourelatos D, Tsiftsoglou AS, Giassin NP, Mioglou E, Garefis P. Genotoxic and cytotoxic effects of different types of dental cement on normal cultured human lymphocytes. Mutat Res. 2009;672(2):103-12.

3- Chen RS, Liu CC, Tseng WY, Jeng JH, Lin CP. Cytotoxicity of three dentin bonding agents on human dental pulp cells. J Dent. 2003;31(3):223-9.

4- Eldeniz AU, Mustafa K, Ørstavik D, Dahl JE. Cytotoxicity of new resin-, calcium hydroxide- and silicone-based root canal sealers on fibroblasts derived from human gingiva and L929 cell lines. Int Endod J. 2007;40(5):329-37.

5- Ergün G, Dogan A, Özkul A, Demirel E. Glass ionomer cement and composite cements: cytotoxicity effect. Balk J Stom. 1999;3(2):103-5.

6- Ergün G, Eğilmez F, Uçtaşli MB, Yilmaz S. Effect of light curing type on cytotoxicity of dentine-bonding agents. Int Endod J. 2007;40(3):216-23.

7- Feng L, Carvalho R, Suh BI. Insufficient cure under the condition of high irradiance and short irradiation time. Dent Mater. 2009;25(3):283-9.

8- Franz A, König F, Skolka A, Sperr W, Bauer P, Lucas T, et al. Cytotoxicity of resin composites as a function of interface area. Dent Mater. 2007;23(11):1438-46.

9- Franz A, Konradsson K, König F, Van Dijken JW, Schedle A. Cytotoxicity of a calcium aluminate cement in comparison with other dental cements and resin-based materials. Acta Odontol Scand. 2006;64(1):1-8.

$10-$ Goldberg M. In vitro and in vivo studies on the toxicity of dental resin components: a review. Clin Oral Investig. 2008;12(1):1-8. 11- Hikage S, Sato A, Suzuki S, Cox CF, Sakaguchi K. Cytotoxicity of dental resin monomers in the presence of $\mathrm{S} 9$ mix enzymes. Dent Mater J. 1999;18(1):76-86.
12- Hurrell-Gillingham K, Reaney IM, Brook I, Hatton PV. In vitro biocompatibility of a novel Fe2O3 based glass ionomer cement. J Dent. 2006;34(8):533-8.

13- International Organization for Standardization. ISO 10993-5: biological evaluation of medical devices. Part 5: tests for in vitro cytotoxicity. Geneva:The Organization; 2009.

14- International Organization for Standardization. ISO 1099312: biological evaluation of medical devices. Part 12: sample preparation and reference materials. Geneva: The Organization; 2002.

15- Jandt KD, Mills RW, Blackwell GB, Ashworth SH. Depth of cure and compressive strength of dental composites cured with blue light emitting diodes (LEDs). Dent Mater. 2000;16(1):41-7. 16- Jorge $\mathrm{JH}$, Giampaolo ET, Vergani $\mathrm{CE}$, Machado $\mathrm{AL}$, Pavarina AC, Carlos IZ. Effect of post-polymerization heat treatments on the cytotoxicity of two denture base acrylic resins. J Appl Oral Sci. 2006;14(3):203-7.

17- Kan KC, Messer LB, Messer HH. Variability in cytotoxicity and fluoride release of resin-modified glass-ionomer cements. J Dent Res. 1997;76:1502-7.

18- Khalil AM, Da'dara AA. The genotoxic and cytotoxic activities of inorganic fluoride in cultured rat bone marrow cells. Arch Environ Contam Toxicol. 1994;26(1):60-3.

19- Lee IB, Um CM. Thermal analysis on the cure speed of dual cured resin cements under porcelain inlays. J Oral Rehabil. 2001;28(2):186-97.

20- Lönnroth EC, Dahl JE. Cytotoxicity of liquids and powders of chemically different dental materials evaluated using dimethylthiazol diphenyltetrazolium and neutral red tests. Acta Odontol Scand. 2003;61(1):52-6.

21- Lopes LG, Franco EB, Pereira JC, Mondelli RF. Effect of lightcuring units and activation mode on polymerization shrinkage and shrinkage stress of composite resins. J Appl Oral Sci. 2008;16(1):35-42.

22- Moszner N, Salz U, Zimmermann J. Chemical aspects of selfetching enamel-dentin adhesives: a systematic review. Dent Mater. 2005;21(10):895-910.

23- Obici AC, Sinhoreti MA, Goes MF, Consani S, Sobrinho LC. Effect of the photo-activation method on polymerization shrinkage of restorative composites. Oper Dent. 2002;27(2):192-8.

24- Pameijer $\mathrm{CH}$, Stanley $\mathrm{HR}$, Ecker G. Biocompatibility of a glass ionomer luting agent. 2. Crown cementation. Am J Dent. $1991 ; 4(3): 134-41$.

25- Peutzfeldt A, Sahafi A, Asmussen E. Characterization of resin composites polymerized with plasma arc curing units. Dent Mater. 2000;16(5):330-6.

26- Piva E, Correr-Sobrinho L, Sinhoreti MA, Consani S, Demarco FF, Powers JM. Influence of energy density of different light sources on Knoop hardness of a dual-cured resin cement. J Appl Oral Sci. 2008;16(3):189-93.

27- Price RB, Felix CA, Andreou P. Evaluation of a secondgeneration LED curing light. J Can Dent Assoc. 2003;69(10):666. 28- Schmalz G, Arenholt-Bindslev D. Biocompatibility of dental materials. Berlin: Springer-Verlag; 2009.

29- Uhl A, Mills RW, Vowles RW, Jandt KD. Knoop hardness depth profiles and compressive strength of selected dental composites polymerized with halogen and LED light curing technologies. J Biomed Mater Res. 2002;63(6):729-38.

30- Yoshii E. Cytotoxic effects of acrylates and methacrylates: relationships of monomer structures and cytotoxicity. J Biomed Mater Res. 1997;37(4):517-24. 